\title{
Tardy ulnar nerve palsy following a neglected childhood lateral epicondyle fracture non-union and resultant cubitus valgus deformity
}

\author{
Kunal Mohan, Prasad Ellanti, Omar Hadidi, Catherine Bossut
}

Department of Trauma and Orthopaedics, Saint James's Hospital, Dublin, Ireland

\section{Correspondence to Dr Kunal Mohan, kmohan@tcd.ie}

Accepted 31 October 2018

\section{DESCRIPTION}

A 30-year-old male right-hand dominant barber was referred to an upper limb orthopaedic clinic with a 2-year history of worsening intermittent pain, left hand weakness, loss of grip strength, paraesthesia and mild clawing of his ring and little fingers, limiting his activities of daily living. There was no recent trauma to his left arm or cervical spine; however, the patient described a previously conservatively managed left elbow fracture 24 years previously.

Inspection identified a cubitus valgus elbow deformity of approximately $18^{\circ}$, with an elbow range of motion of $0^{\circ}$ extension and $135^{\circ}$ flexion. Examination revealed severe wasting of both the ulnar aspect of the forearm and intrinsic muscles of the hand, particularly apparent in the first dorsal interosseous space, in addition to flattening of the hypothenar eminence and correctable fourth and fifth digit claw deformities (figure 1). A 4/5 grade power was noted in finger abduction and adduction, with a concomitant sensory deficit to the ulnar aspect of the ring and little fingers. Tinel's test at the elbow and Froment's sign were positive.

Plain radiographic assessment of the elbow revealed visible non-union of the lateral epicondyle (figure 2). Nerve conduction studies confirmed a severe combined sensory and motor ulnar neuropathy. The patient was hence counselled and offered

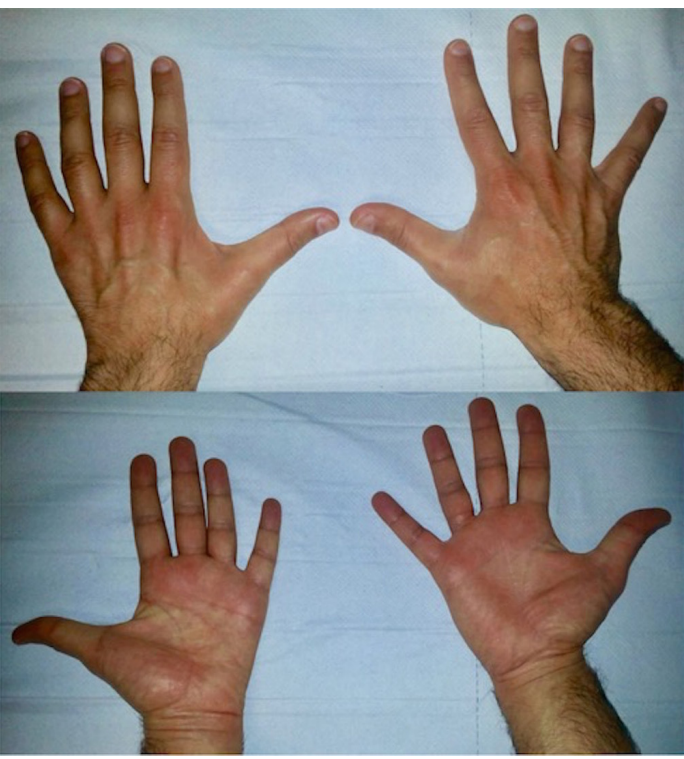

Figure 1 Dorsal and palmar comparison views of left and right hands.

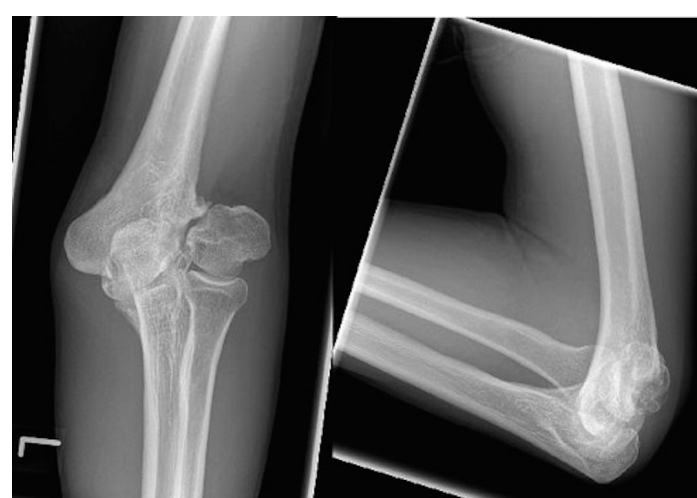

Figure 2 Anteroposterior and lateral plain radiographs of left elbow.

urgent surgical intervention consisting of an ulnar nerve decompression and subcutaneous nerve transposition at the level of the elbow, with a view to potentially arresting the progressive deterioration in symptoms and hand function. The non-union was not addressed as the patient displayed no elbow symptoms or limitation. Surgery was thus undertaken with excellent postoperative results, namely improvement in both strength, function and complete resolution of the sensory deficit and pain in his little and ring fingers.

Upper limb neuropathies are commonly seen and can lead to pronounced impairment and disability. ${ }^{1}$ While ulnar neuropathies at the level of the elbow are frequently compressive, ${ }^{1}$ tardy ulnar nerve palsies, in which a prolonged distracting stress to the nerve transpires as a result of a cubitus valgus deformity of the elbow ensuing following initial elbow lateral epicondyle fracture ${ }^{2}$ can also occur. Management of this condition with ulnar transposition can improve symptoms, as was evidenced in this case. ${ }^{2}$

Typically, those with ulnar neuropathy tend to complain of generalised hand weakness and loss of dexterity, ${ }^{3}$ in addition to symptoms of weakness and paraesthesia in the ulnar nerve distribution. ${ }^{3}$ While an ulnar nerve neuropathy can precipitate visible deformity and muscle atrophy on examination, this is usually witnessed in less than $12 \%$ of those with a confirmed ulnar neuropathy, ${ }^{3}$ with these signs usually only occurring in those with a prolonged duration of symptoms.

The described case clearly displayed features of deformity traditionally associated with ulnar nerve palsy, with evidence of interosseous muscle wasting 
and hypothenar eminence flattening easily appreciated on general inspection, particularly when compared with the unaffected limb (figure 1). Given the relative rarity in which these features are encountered, ${ }^{3}$ appreciation of the demonstrated clinical signs may aid in improved future diagnosis, hence improving management of this potentially debilitating condition.

\section{Learning points}

Tardy ulnar neuropathy at the level of the elbow can occur as a result of cubitus valgus deformity following lateral epicondyle fracture non-union.

- Signs of intrinsic muscle atrophy in the hand as a result of ulnar neuropathy are not frequently seen.

- Recognition of the signs of intrinsic hand muscle wasting may aid detection, diagnosis and management of ulnar neuropathy.

Acknowledgements Many thanks to the patient for approving publication of this case.
Contributors KM is both the primary and corresponding author and was hence involved in information accumulation, data synthesis and preparation of draft and final manuscripts. PE is the second author and was involved in patient postoperative clinical review, as well as information accumulation and review of the draft and final manuscripts. $\mathrm{OH}$ is the third author and was involved in information accumulation and patient consent. CB is the senior supervising author and was involved in patient preoperative clinical assessment, surgical management and postoperative clinical review, as well as information accumulation and review of the draft and final manuscripts.

Funding The authors have not declared a specific grant for this research from any funding agency in the public, commercial or not-for-profit sectors.

Competing interests None declared.

Patient consent Obtained.

Provenance and peer review Not commissioned; externally peer reviewed.

\section{REFERENCES}

1 Latinovic R, Gulliford MC, Hughes RA. Incidence of common compressive neuropathies in primary care. J Neurol Neurosurg Psychiatry 2006;77:263-5.

2 Mortazavi SM, Heidari P, Asadollahi S, et al. Severe tardy ulnar nerve palsy caused by traumatic cubitus valgus deformity: functional outcome of subcutaneous anterior transposition. J Hand Surg Eur Vol 2008;33:575-80.

3 Drake ML, Hensley DT, Chen WC, et al. Muscle atrophy at presentation of cubital tunnel syndrome: demographics and duration of symptoms. Hand 2017;12:64-7.

Copyright 2018 BMJ Publishing Group. All rights reserved. For permission to reuse any of this content visit http://group.bmj.com/group/rights-licensing/permissions.

BMJ Case Report Fellows may re-use this article for personal use and teaching without any further permission.

Become a Fellow of BMJ Case Reports today and you can:

- Submit as many cases as you like

- Enjoy fast sympathetic peer review and rapid publication of accepted articles

- Access all the published articles

Re-use any of the published material for personal use and teaching without further permission

For information on Institutional Fellowships contact consortiasales@bmjgroup.com

Visit casereports.bmj.com for more articles like this and to become a Fellow 